\title{
Multisystemic Treatment of Serious Behaviour Problems in Youth: Sustainability of Effectiveness Two Years after Intake
}

\section{Terje Ogden \& Kristine Amlund Hagen}

The Norwegian Centre for Studies of Conduct Problems and Innovative Practice, Unirand, PO Box 1565, Vika, N-0118 Oslo, Norway E-mail: terje.ogden@atferd.unirand.no

\begin{abstract}
Background: Multisystemic Treatment (MST) is an intensive home- and community based intervention for youths with serious behaviour problems. The aim of this study was to examine the effectiveness of MST compared to 'regular services' (RS) two years after intake to treatment. In particular, our goals were to investigate whether MST was successful at preventing placement out of home, and to examine reductions in behaviour problems in multi-informant assessments. Method: Participants were 75 adolescents who were randomly assigned to MST or Regular Child Welfare Services (RS) at 3 sites across Norway. Data were gathered from youths, caregivers and teachers. Results: MST was more effective than RS in reducing out of home placement and behavioural problems. Discussion: The sustainability of treatment effects was evident, supporting the MST approach to the treatment of serious behavioural problems in youth. Site differences and the moderating effects of age and gender are discussed.
\end{abstract}

Keywords: Serious behaviour problems; multisystemic treatment; follow-up study; treatment effectiveness

\section{Introduction}

A number of initiatives have been launched in the last decade in search of effective interventions in the treatment of antisocial children and youths (Aos et al., 2004; Ferrer-Wreder et al., 2004; Loeber $\&$ Farrington, 1998). In Norway, as well as in other countries, serious behaviour problems in adolescence constitute a major cause for concern and carry substantial personal and societal costs. Surveys of the Norwegian Child Welfare and the Mental Health Services show that neither has the necessary resources, support, or competencies to handle the most difficult of youngsters (Storvoll, 1997; Nygren, 2000).

The introduction of Multisystemic Treatment (MST) in Norway represented an increased capacity for treatment as well as offering a new direction in treatment methods by emphasizing multi-systemic interventions. Since 1999, MST has been implemented nationwide and approximately 1500 youths and families have received treatment.

Multisystemic treatment represents a family and community based alternative to individual and group treatment or to incarceration and placement out of home. In line with a socio-ecological framework, children's and adolescents' behaviour must be considered in light of the social systems in which they are embedded. Following this theoretical perspective, it makes little sense to treat young people exclusively and isolated from their normal environments. MST intervenes by using the family as a starting point and delivers treatment in a highly individualised and comprehensive manner by addressing the key predictors of antisocial behaviour, the sources of conflict within the family, and the adolescent's functioning in school (Henggeler et al., 1998; Huey et al., 2000; Elliott, 1998).

Earlier outcome studies in the United States show that MST is highly effective in reducing recidivism, drug-related arrests, severity of crimes and out of home placement in addition to improving family cohesion and adaptation (Halliday-Boykins \& Henggeler, 2001; Borduin et al., 1995; Henggeler \& Lee, 2003; Henggeler et al., 1997; Huey et al., 2000; Henggeler, Melton, \& Smith, 1992). Equivocal results have been reported in improving psychosocial functioning, drug use and school attendance, but only modest results in enhancing peer relations, self-esteem, and self reported behaviour problems in youth. It is unclear why improvements in adolescents' self-reported problems and peer relations are weaker, though one plausible explanation is the youth's persisting affiliation with his or her deviant peer group.

Because MST is a relatively short term intervention programme (4 to 6 months) with no regular after care, the sustainability of the treatment results has been called into question. Positive long term outcomes, however, are achieved by changing the natural ecology of the youth, such as family processes, peer relations and leisure activities, which in turn contributes to a generalisation of treatment efforts. Through treatment, adolescents and their families are given the tools necessary to prevent or tackle challenges, some of which are inevitable. Moreover, while families may have some remaining issues after treatment, they become better equipped to handle conflicts in general and this capacity is believed to persist beyond intervention (Cunningham et al., 1999; Henggeler et al., 1998). 
Empirically, studies show sustained reductions in reoffending by MST participants varying between 25 and $70 \%$ compared to the control group (Henggeler et al., 1992, 1997). For instance, Henggeler et al. (1992) found a doubling of the survival rate of re-arrests for the MST youths compared to RS youths, 2 years post treatment. Significant reductions in acts of crime favouring MST have been found in studies conducted 4 years (Borduin et al., 1995) and even 13 years post treatment (Schaeffer \& Borduin, 2005).

As studies are transported from university-based demonstration projects (efficacy studies) to independent, community-based programs (effectiveness studies), treatment adherence, a pivotal aspect of programme implementation, seems to become increasingly difficult to achieve. In fact, a general finding in effectiveness studies is a relatively strong negative association between fidelity monitoring and youth behavioural problems (Schoenwald et al., 2000; Henggeler, Pickrel, \& Brondino, 1999; Henggeler et al., 1997; Henggeler \& Schoenwald, 1999). Even within single studies, using multi-site designs, site differences in adolescent and family outcomes are related to level of treatment fidelity (Ogden \& Halliday-Boykins, 2004; Leschied \& Cunningham, 2002).

The present study builds on the previously reported short-term outcome study of the Norwegian MST project (Ogden \& Halliday-Boykins, 2004). The results were positive but indicated that treatment outcomes differed across sites. In order to address the possibility that certain sites may have been implementing MST more effectively than others, MST treatment fidelity was examined using the Therapist Adherence Measure (TAM; Henggeler \& Borduin, 1992). It turned out that the site with the poorest MST outcomes reported having been unable to collect adherence measures, making it impossible to evaluate its treatment integrity. It was therefore questionable whether MST was being implemented at this site at all and led us to concentrate on analyses from three of the four sites. TAM scores also differed significantly across the three remaining sites; the site with the lowest scores had the least favourable outcomes and the one with the highest score demonstrated the best outcomes. Accordingly, differential MST treatment effects across sites are likely due in part to variability in the quality of treatment implementation. This is consistent with previous MST research that has shown that outcomes are linked to treatment fidelity (Henggeler et al., 1997; Huey et al., 2000) and the findings illustrate the importance of examining site effects in multi-site studies.

The present study was carried out as an independent study, in that the authors did not participate in the treatment, training, or supervision of MST therapists, nor did they have any contact with the participants (Lipsey, 1999). While earlier MST studies generally have failed to detect moderating effects of gender, age, ethnicity, or SES (Borduin et al., 1995), researchers are nonetheless encouraged to include such variables in their investigations, especially as programmes move into the community (Curtis, Ronan, \& Borduin, 2004). The overall aim of the present MST multi-site investigation was to examine the effectiveness of MST compared to 'regular services' (RS) by collecting data from the youths themselves, their parents and teachers.
Specific goals were to (1) investigate whether MST was successful in preventing out-of-home placement and (2) examine reductions in behaviour problems, such as delinquency. Additionally, we examined site differences in treatment effectiveness and possible moderating effects of age and gender.

\section{Method}

\section{Participants}

The number of participants was $75 ; 48$ boys and 27 girls, who averaged 15.07 years of age at intake $(S D=$ 1.36). The retention rate at follow-up was $69 / 75$ (92\%). Almost all caregivers (74/75) had a Norwegian background. At the time of referral, most of the adolescents lived at home, either with both of their parents $(n=16$, $21 \%)$, with their mother only ( $n=26,35 \%)$, father only $(n=2,3 \%)$, with their mother and another adult $(n=$ $13,17 \%)$, or with their father and another adult $(n=4$, $5 \%)$. Other youths lived in hospitals or other institutions $(n=8,11 \%)$ or foster homes $(n=6,8 \%)$.

\section{Design and procedures}

Participants were referred from the municipal Child Welfare services to the corresponding specialist services at the county municipal level for serious behaviour problems. Three sites participated in the present study and each site contributed 25 cases. MST treatment was delivered by four MST teams and each team had three or four therapists and a clinical supervisor and worked exclusively with MST. All MST therapists had a professional education equivalent to a master's or bachelor's degree in social work, psychology or education and some also had additional training in family therapy. Two of the three MST clinical supervisors were licensed psychologists, and one had a degree in social work.

Recruitment of participants was made via the Municipal Child Welfare Services. Referral to these services can be made by the police, school personnel or family members. Inclusion criteria were: (1) problem behaviour such as law-breaking or other antisocial acts, serious academic difficulties, dysfunctional interpersonal relations, verbal aggression and threats of hurting others; (2) age between 12 and 17 years; (3) parents (or parent surrogates) were sufficiently involved and motivated to start MST. Exclusionary criteria were: (1) ongoing treatment by another agency; (2) substance abuse without other antisocial behaviour (although youths with substance abuse in combination with other antisocial behaviours were not excluded); (3) sexual offending; (4) autism, acute psychosis, or imminent risk of suicide; (5) presence of the youth in the home posed a serious risk to the youth or to the family; and (6) ongoing investigation by the municipal child welfare services. No youth referred was excluded according to any of these six criteria. All youths who met study inclusion criteria were invited to participate in the study and all eligible families agreed to participate. Data were collected at a location suited to the adolescents' or families' needs (e.g. in the home). At follow-up, local research assistants who were trained and paid by the principal investigator collected the data. 
The families were randomly assigned to treatment conditions, each having a $6 / 10$ chance of receiving MST and a 4/10 chance of receiving regular Child Welfare Services (RS). This weighted randomisation procedure was utilised because it was assumed that some of the MST families would prematurely drop out from treatment or withdraw from the outcome study, as MST was so divergent from usual care.

Assessments were administered at study entry (prior to randomisation) and after termination of MST treatment (average treatment time was 24.3 weeks ranging from 7 to 38 weeks) or approximately 6 months after intake for the RS group. The follow-up data were collected as close as possible to 2 years after intake for each case. The participating families were given a small economic compensation for completing each assessment. Informed consent was obtained from all adolescents, parents, and teachers.

\section{Measures}

Out-of-home placement. The youth's placement was measured using two parent-reported items that asked where the youth was living (1) at the time of the assessment and (2) most of the previous 6 months. We maintain that the latter is a better indicator of positive functioning as it attests to a more stable condition. Response options included various single- and twoparent home combinations (e.g. both parents, mother and other partner, father only, and independently under supervision), as well as out-of-home placements (e.g. foster parents, institution, hospital). For both items, living situation was dichotomized, such that youths who were living at home were compared to those who were placed out of home. Participants above 17 years of age who were living on their own or in an educational setting under supervision and with the consent of their caregivers were included in the living at home' category, as this was considered a positive outcome.

Child Behaviour Checklist (CBCL). Youth behaviour was assessed by caregiver, adolescent and teacher ratings on the CBCL (Achenbach, 1991a), Youth Self-Report (YSR) (Achenbach, 1991b) and Teacher's Report Form (TRF) (Achenbach, 1991c). The CBCL and associated measures are applicable to children aged 4 to 18 years and includes three broad band behaviour problem scales (Internalising, Externalising, and Total Behaviour Problems). This instrument has demonstrated acceptable validity in Norway and has been standardised for use with Norwegian children and youths (Nøvik, 1999). In the present study, the internal consistency was high for both internalising and externalising behaviour for all respondents ( $\alpha$ 's range from .81 to .94). In the follow-up study, the 89-item problem behaviour scale was utilised in order to have one matching assessment from each of the informant groups.

Self-Report Delinquency Scale. The Self-Report Delinquency scale (SRD; Elliott et al., 1983) is a well-known and validated self-report measure used in previous MST studies (Henggeler et al., 1998), as well as in other investigations of adolescent problem behaviour (Heinrichs, 2003; Henggeler et al., 2002; Le Blanc, 1992; Levine \& Jackson, 2004). The SRD assesses covert and overt antisocial behaviour, such as violent offending, general delinquency, and status offences. Inverse transformation of the raw scores was used in the present analyses in an effort to normalise the distribution and retain all scores (Tabachnick \& Fidell, 2001). Internal consistency measured by Cronbach's $\alpha$ was .95 in the present sample.

\section{Interventions}

Multisystemic treatment. Each MST therapist had a low caseload of 3-6 families and the teams were available to the families 24 hours a day, 7 days a week. The referrals to the research project started after the teams had completed their introductory training week and 3-5 pilot cases. MST was terminated when the goals were accomplished in each case. MST was implemented with no major modification of the original intervention model (Henggeler et al., 1998), including the administration of the MST quality assurance system (Henggeler \& Schoenwald, 1999), which monitors therapist and supervisor treatment adherence on a monthly basis (Henggeler \& Borduin, 1992; Schoenwald et al., 2000). Introductory training, quarterly booster sessions and weekly telephone consultation to the teams were provided by MST-services in Charleston, South Carolina, US. Interventions targeted specific, well-defined problems, focused on present conditions, and were action oriented. The clinical procedures include assessment of family functioning, family interventions, changing relations with peers, promoting positive leisure activities as well as academic and social competence in school (Wasserman \& Miller, 1998). The therapists contacted the families on a daily or weekly basis to monitor observable behaviour changes. For a more complete description of the treatment implementation see Ogden and Halliday-Boykins (2004).

Regular Child Welfare Services (RS). Services were delivered by the Municipal and the County Municipal Child Welfare Services, both of which have a broad range of initiatives at their disposal that can be stepped up gradually according to the gravity of the youth's situation. In the present study, youths in the comparison group were delivered the kind of services they would normally have received before MST was introduced, that is regular institutional placement, placement in a crisis institution for assessment and in-home follow-up, supervision by a social worker in their homes, or other home-based treatment (approximately $5 \%$ refused the services offered).

\section{Statistical analyses}

Analyses of covariance (ANCOVAs) and chi-square analyses were run to test the effectiveness of MST, 2 years after intake. Given the relatively small sample size, ANCOVA was considered an appropriate method of analysis of intervention effectiveness (Henggeler et al., 2002; Henggeler, Melton, \& Smith, 1992; Leve, Chamberlain, \& Reid, 2005). Pre-treatment assessment (or intake) scores were entered as covariates for the followup outcome measure in order to control for potential differences at intake between the two groups, as well as to account for possible time effects. When intake scores were unrelated to follow-up scores, the adolescents' age 
or gender was used as covariates. In addition, regression analyses were run to investigate the amount of variance explained in the outcome variables by treatment condition and respective covariates. These analyses also offer an alternative method of measuring effect. For the teacher data, we tested a structural model with age, intake- and follow-up scores parameters using expectation-maximisation procedure to account for missing data, in addition to the analysis of covariance.

\section{Results}

\section{Analysis of attrition}

The randomisation procedure resulted in 46 families being assigned to multisystemic treatment and 29 families to regular services. From intake assessment to follow-up, 3 MST families and 3 RS families withdrew from the research project, resulting in a retention rate of $69 / 75$ (92\%). There were no significant differences between the families that withdrew from the research project and the remaining participants on demographic or treatment assessment scores on psychosocial variables.

\section{Placement out of home}

The results suggested that MST participants were less likely to have been placed out of the home than were their RS counterparts. A chi-square analysis showed that at follow-up, 33/46 (72\%) of the MST youths and $15 / 29(52 \%)$ of the RS youths were living at home or under supervision by their caregivers $\left(\chi^{2}=3,093\right.$, $p<.07)$. There was a significant difference among MST and RS adolescents who were living at home at intake $(n=61)$. Of these, $31 / 39(80 \%)$ of the MST adolescents had still been living at home the past 6 months at follow-up, compared to only $12 / 22$ (55\%) of the RS adolescents $\left(\chi^{2}=4,21, p<.05\right.$, see Table 1$)$.

The living situation of adolescents above $(n=52)$ and below $(n=23)$ the age of 17 were compared. Older adolescents who received MST were significantly more likely to have lived at home during the past 6 months than adolescents receiving regular services $\chi^{2}=3.99$,

Table 1. Chi-square analyses of youth living situation by treatment condition

\begin{tabular}{|c|c|c|c|c|}
\hline \multirow[b]{2}{*}{ Variable } & \multirow{2}{*}{$\begin{array}{l}\text { Regular } \\
\text { Services }\end{array}$} & \multirow{2}{*}{$\begin{array}{l}\text { Multisystemic } \\
\text { Treatment }\end{array}$} & \multicolumn{2}{|c|}{$\begin{array}{l}\text { Treatment } \\
\text { Effect }\end{array}$} \\
\hline & & & $\chi^{2}$ & $p$ \\
\hline \multicolumn{5}{|c|}{ A) All youths $(N=75)$} \\
\hline \multicolumn{5}{|c|}{ Living situation last 6 mos. } \\
\hline Out of home & $48 \%$ & $28 \%$ & 3.09 & .07 \\
\hline At home & $52 \%$ & $72 \%$ & & \\
\hline \multicolumn{5}{|c|}{ Living situation current } \\
\hline Out of home & $45 \%$ & $26 \%$ & 2.81 & .08 \\
\hline At home & $55 \%$ & $74 \%$ & & \\
\hline \multicolumn{5}{|c|}{ B) Youths who were living at home at intake $(80 \%, n=61)$} \\
\hline \multicolumn{5}{|c|}{ Living situation last 6 mos. } \\
\hline Out of home & $45 \%$ & $20 \%$ & 4.21 & .04 \\
\hline At home & $55 \%$ & $80 \%$ & & \\
\hline \multicolumn{5}{|c|}{ Living situation current } \\
\hline Out of home & $45 \%$ & $23 \%$ & 3.28 & .065 \\
\hline At home & $55 \%$ & $77 \%$ & & \\
\hline
\end{tabular}

$p<.05)$. A gender by treatment analysis indicated that of boys $(n=48)$ receiving MST, $79.3 \%$ had been living at home the past 6 months, compared to only $36.8 \%$ of the boys receiving regular services $\left(\chi^{2}=8.83, p<.01\right)$. There was no significant difference between MST and RS for girls ( $n=27$, see Table 2$)$.

\section{Parent reports}

Means, standard deviations, and $F$-values by treatment group for primary outcome variables are presented in Table 3. Parents of adolescents receiving MST rated their children significantly lower on the CBCL total problem scale than did the parents of youths receiving regular services, after controlling for their pre treatment assessment scores $\left(F_{1,64}=4.01, p<.05\right)$. Regression analysis indicated that treatment condition significantly accounted for about $6 \%$ of the variance in the outcome variable, over and above the variance explained by the CBCL scores at intake. Results also indicated a significant difference between MST and RS youths on the internalising problem scale after controlling for their internalising scores at intake, $\left(F_{1,56}=9.72, p<.01\right)$. Regression analyses suggested that internalising scores at intake significantly predicted $6 \%$ of the variance in the follow-up scores, and treatment condition significantly predicted an additional $9 \%$ of the variance in internalising scores. There were no differences in externalising scores between treatment conditions. Time effects for all CBCL measures were found to be significant from intake to follow-up (all scales, $p<.001$ ).

\section{Youth reports}

Adolescents receiving MST scored significantly lower on the Self Report Delinquency Scale (SRD) than did adolescents receiving regular services, after controlling for their SRD pre-assessment scores at intake $\left(F_{1,53}=\right.$ 4.56, $p<.05$, see Table 3 ). In the regression model, SRD scores at intake significantly predicted $15 \%$ of the variance in the follow-up outcome variable. Treatment condition significantly predicted another $7 \%$ over and above the variance explained by the SRD intake scores.

There were no significant differences between treatment conditions in scores on the total problem scale of

Table 2. Chi-square analyses of treatment condition by age-level and treatment condition by gender on youth living situation

\begin{tabular}{|c|c|c|c|c|}
\hline \multirow[b]{2}{*}{ Variable } & \multirow{2}{*}{$\begin{array}{l}\text { Regular } \\
\text { Services }\end{array}$} & \multirow{2}{*}{$\begin{array}{c}\text { Multisystemic } \\
\text { Treatment }\end{array}$} & \multicolumn{2}{|c|}{$\begin{array}{l}\text { Treatment } \\
\text { Effect }\end{array}$} \\
\hline & & & $\chi^{2}$ & $p$ \\
\hline \multicolumn{5}{|c|}{ Age by treatment group } \\
\hline \multicolumn{5}{|c|}{ Below $17(n=23)$} \\
\hline Out of home & $43 \%$ & $38 \%$ & .06 & n.s \\
\hline At home & $57 \%$ & $62 \%$ & & \\
\hline \multicolumn{5}{|l|}{ Above $17(n=52)$} \\
\hline Out of home & $50 \%$ & $23 \%$ & 3.99 & .045 \\
\hline At home & $50 \%$ & $77 \%$ & & \\
\hline \multicolumn{5}{|c|}{ Gender by treatment group } \\
\hline \multicolumn{5}{|c|}{ Girls $(n=27)$} \\
\hline Out of home & $20 \%$ & $41 \%$ & 1.27 & n.s. \\
\hline At home & $80 \%$ & $59 \%$ & & \\
\hline \multicolumn{5}{|l|}{ Boys $(n=48)$} \\
\hline Out of home & $63 \%$ & $21 \%$ & 8.83 & .004 \\
\hline At home & $37 \%$ & $79 \%$ & & \\
\hline
\end{tabular}


Table 3. Means, standard deviations, and analyses of covariance and time effects of primary outcome variables by treatment conditions

\begin{tabular}{|c|c|c|c|c|c|c|c|c|}
\hline \multirow[b]{2}{*}{ Variable } & \multicolumn{2}{|c|}{ Regular Services } & \multicolumn{2}{|c|}{ Multisystemic Treatment } & \multicolumn{2}{|c|}{$\begin{array}{c}\text { Treatment } \\
\text { Effect }\end{array}$} & \multicolumn{2}{|c|}{ Time Effect } \\
\hline & $\begin{array}{c}\text { Intake } \\
\text { Mean (SD) }\end{array}$ & $\begin{array}{l}\text { Follow-up } \\
\text { Mean }(S D)\end{array}$ & $\begin{array}{c}\text { Intake } \\
\text { Mean }(S D)\end{array}$ & $\begin{array}{l}\text { Follow-up } \\
\text { Mean (SD) }\end{array}$ & $F$ & $p$ & $t$ & $p$ \\
\hline \multicolumn{9}{|l|}{ Youth reports } \\
\hline Self Report Delinquency ${ }^{a}$ & $66.57(62.17)$ & $44.92(56.44)$ & $59.39(62.28)$ & $30.57(54.06)$ & 4.56 & .037 & 1.07 & ns \\
\hline YSR 89-Item Scale & $47.75(17.42)$ & $41.00(22.17)$ & $56.37(20.19)$ & $41.66(19.35)$ & .122 & ns & 3.69 & $<.001$ \\
\hline YSR Externalising & $22.68(8.13)$ & $15.56(10.32)$ & $25.80(9.47)$ & $15.93(8.26)$ & .004 & ns & 7.01 & $<.001$ \\
\hline YSR Internalising & $12.59(7.21)$ & $12.92(8.96)$ & $15.86(9.25)$ & $13.05(7.96)$ & .103 & ns & 1.39 & ns \\
\hline \multicolumn{9}{|l|}{ Parent reports } \\
\hline CBCL 89-Item Problem Scale & $53.59(20.93)$ & $41.22(23.69)$ & 53.49 (18.59) & $30.60(18.32)$ & 4.01 & .050 & 6.87 & $<.001$ \\
\hline CBCL Externalising & 23.69 (7.93) & $14.39(9.62)$ & $24.24(8.24)$ & $12.88(8.85)$ & .73 & ns & 8.32 & $<.001$ \\
\hline CBCL Internalising & $15.23(6.83)$ & $14.61(10.97)$ & $17.83(8.07)$ & $8.88(6.04)$ & 9.72 & .003 & 4.18 & $<.001$ \\
\hline \multicolumn{9}{|l|}{ Teacher reports $^{\mathrm{b}}$} \\
\hline TRF 89-Item Problem Scale & $38.63(19.75)$ & $36.45(17.67)$ & $39.72(19.53)$ & $20.20(12.50)$ & 40.30 & $<.001$ & 6.51 & $<.001$ \\
\hline TRF Externalising & $19.63(11.96)$ & $20.39(10.31)$ & $21.29(12.73)$ & $11.32(6.69)$ & 29.62 & $<.001$ & 4.05 & $<.001$ \\
\hline TRF Internalising & $13.27(6.66)$ & $13.69(6.13)$ & $13.16(8.60)$ & $6.96(5.65)$ & 31.66 & $<.001$ & 4.12 & $<.001$ \\
\hline
\end{tabular}

${ }^{a}$ Values here are presented prior to normalisation

${ }^{b}$ Expectation-maximisation procedure is used in analysis of teacher reports. Results from analyses of covariance are presented here

the YSR, or in levels of internalising and externalising behavioural problems as rated by the youths themselves. Paired sample $t$-tests indicated significant time effects for the total problem scale $\left(t_{1,62}=3.69\right.$, $p<.001)$, and for the externalising sub-scale of the YSR $\left(t_{1,63}=7.01, p<.001\right)$. As a group, adolescents in both the MST and RS conditions scored significantly lower at follow-up than they did at pre-assessment on both of these YRS-scales.

\section{Teacher reports}

At follow-up, 51 of the original participants were attending school, though reliable teacher assessments were collected from only 29 of these. Missing versus non-missing teacher reports were dummy coded and then predicted by key measures. Logistic regression analyses suggested that adolescents for whom we were missing teacher reports were on average older and scored significantly lower on the total problem scale of the TRF at pre-assessment. The two groups (missing vs. non-missing) did not differ on any of the CBCL, YSR or SRD scales, nor did they differ in treatment condition assignment, gender, or living situation.

We tested a structural model in which missing teacher reports at follow-up were estimated using multiple imputation procedure (expectation-maximisation, EM) The EM method is considered an accurate and realistic method of handling for missing data (Tabachnick \& Fidell, 2001; Capaldi, Stoolmiller, Clark, \& Owen, 2002), primarily because it does not capitalise on deflated within-subjects variance. This procedure operates by creating new expected scores based on best guesses derived from the non-missing data (e.g. through correlations). Several random samples with replacement are taken and the average estimates of these are then used to make up a new distribution of the data. Age and intake scores were used as predictors in the imputation procedure, as they were both related to the likelihood of having missing teacher reports at follow-up.

The treatment condition parameter was significantly related to every teacher outcome measure (total problem scale, externalising, and internalising), favouring MST. For the total problem scale, $25 \%$ of the variance was accounted for by the model. For the internalising and externalising sub-scales, $27 \%$ and $25 \%$ of the variances were accounted for, respectively, by the models. The analysis of covariance, again using the EM procedure, yielded the same results; MST was more effective than RS for all TRF scales (see Table 3). Controlling for gender, teachers rated MST youths significantly lower on internalising problems than they did RS youths $\left(F_{1,29}=4.84, p<.05\right)$.

\section{Clinical significance and effect sizes}

As an indicator of practical significance, the number of youths scoring in the normal range of CBCL total problem behaviour scale (112 items) was calculated. The parent ratings on the CBCL were compared to Norwegian (Nøvik, 1999) and Swedish norms (Larsson \& Frisk, 1999) in which scores below the 90th percentile in the population are considered in the normal range. Higher scores are in the pathological or treatment range (Nygren, 2000). At intake, $8.9 \%$ of the MST group and $13.9 \%$ of the RS group scored in the 'normal range'. At post-treatment assessment, the proportion of MST youths scoring in the normal range had increased to $37.8 \%$ compared to $21.4 \%$ in the RS group, and at follow-up the proportions were $53.5 \%$ and $39.1 \%$ respectively. Thus, the number of youths scoring in the normal range increased for both groups, but at a considerably higher rate in the MST group. Effect sizes (Cohens $d$ ) is another indicator of practical significance in which mean differences in scores at follow-up between treatment conditions are divided by the pooled standard deviation. The effect sizes were 0.26 for self reported delinquency (SRD), 0.50 for parents' CBCL ratings and 0.68 for teachers' TRF ratings, favouring MST. The youths' YSR ratings, however, showed zero effect.

\section{Discussion}

The current investigation demonstrated that multisystemic treatment resulted in favourable effects on serious behaviour problems in adolescents, 2 years post 
treatment. Compared to youths receiving regular interventions from the Child Welfare Services, MST participants scored significantly lower on primary outcome measures of behavioural problems and delinquency as reported by the youths themselves, their parents and their teachers. Moreover, MST had positive effects on the adolescents' living situation. Our results also emphasize the importance of adhering to treatment protocol in studies of programme evaluation as evident from marked site differences. On a few outcome variables, treatment effects were not observed because significant positive changes in the MST group were paralleled in the comparison group.

The fact that MST families were able to keep their adolescents at home to a greater extent than were RS families was consistent with our expectations because a core principle of MST is to enhance family cohesion. This finding is also consistent with results from earlier MST studies (Henggeler et al., 1992). MST was particularly effective at keeping boys and older youths at home. While MST is tailored to the individual family's needs, it was originally designed for antisocial boys and this may explain the moderating effect of gender. Alternatively, the girls in our sample may have responded better to the regular services in relation to this outcome, though we caution placing too much emphasis on group differences among girls as these sub-groups were small. On the remaining outcome variables, however, the girls and the boys in the MST treatment condition had an equally positive development relative to the RS group. Some research has suggested that addressing the anti-social behaviour typical in girls (e.g. relational aggression) may prove more effective even for girls with a history of criminal involvement (Leve, Chamberlain, \& Reid, 2005). Furthermore, there may also be gender differences in the way the involvement with deviant peers affect boys and girls. In future intervention efforts, these potential gender differences need to be considered in more detail, ensuring effective treatment for both boys and girls.

Parents of adolescents receiving MST rated their children significantly lower on the total problem scale of the CBCL than did parents of youths in the comparison group. Among adolescents attending school at followup, those receiving MST were also rated lower by their teachers on the TRF total problem scale. Coupled with the parent reports, the results are consistent with our expectations of the generalising systemic effect of MST. Scores on the YSR, however, did not differ significantly between treatment conditions, though both groups reported lower levels at follow-up. The lack of treatment effects on YSR concurs with earlier MST studies (Curtis et al., 2004).

The parents in the MST group also reported a larger decrease in internalising problem behaviour than did parents in the comparison group. The current study is one of the first investigations to find treatment effects on this measure of psychosocial adjustment. The positive effect of MST on parent reported internalising problems could be explained by MST's emphasis on communication and understanding between family members. It is possible that when family members engage in open discussions and gain cohesion through the MST sessions, parents perceive their adolescents as less troubled and withdrawn, an interpretation that may in turn ameliorate future family interactions and ultimately youth functioning. MST may also have been effective in inhibiting a general upward trend in depressive symptoms found among some adolescents (Schwartz, Gladstone, \& Kaslow, 1998). These favourable outcomes were supported by the teacher ratings, although not reflected in the self-ratings.

The finding that youths receiving MST reported significantly less delinquent behaviour than did their RS counterparts was consistent with our expectations and attests to the effectiveness of the MST procedure. A core principle of MST is to target specific antisocial behaviours, such as those listed on the SRD. These positive results were supported by findings of significantly less acting-out problems as rated by teachers of MST participants. Youths from both treatment conditions, however, reported significantly less externalising problem behaviour at follow up than at intake. This inconsistency in self-reports might be attributable to the fact that while the SRD measures the antisocial behaviours that MST is targeting, the YSR may assess more constitutional characteristics and hence be less sensitive to the specific changes brought about by MST intervention.

Our results indicate that the effectiveness of MST has practical implications in addition to its statistically significant findings. According to Norwegian and Swedish norms, the percentage of youths scoring in the normal range on the CBCL increased from $9 \%$ to $54 \%$ in adolescents receiving MST, an improvement considerably greater than the corresponding increase in the comparison group (14\% to $39 \%$ ). With effect sizes of 0.50 and 0.68 on the parent (CBCL) and teacher (TRF) ratings of problem behaviour, our results compare favourably to the results from a recent meta-analysis of MST (Curtis et al., 2004), in which the calculated average effect size was found to be 0.81 for efficacy projects compared to 0.28 for effectiveness studies. The results of this study also compare favourably to findings from previous meta-analyses of juvenile offender programmes where the overall effectiveness of interventions has shown to be fairly low, especially in regard to long term outcomes (Lösel, 1993). Lipsey (1999), examining more than 400 studies of juvenile offender programmes, found that in effectiveness programmes the average effect size for recidivism was 0.07 , while the efficacy programmes showed a mean recidivism effect size of 0.13 standard deviation units. The relatively high effect sizes at the three sites in the present study are encouraging and may be accounted for by the intensive MST quality assurance system, contributing to a successful transfer of the intervention into the community.

Some limitations to the study should be mentioned. As indicated, there were noticeable site differences in the effectiveness of MST. The most noteworthy issue was that one site was unable to establish a procedure for collecting treatment adherence data (Treatment Adherence Measure, TAM; Henggeler \& Borduin, 1992), making evaluation of treatment integrity impossible. Because measuring treatment fidelity is considered a core component of the MST programme, we argue that this site in fact did not implement MST and decided therefore to exclude it from the follow-up analyses. This decision resulted in a reduction in power, though significant treatment effects of MST were demonstrated at the three remaining sites. It also demonstrated how 
organisations (or contexts) vary in their receptiveness and ability to take on new treatment methods, variations that may need to be studied more closely prior to programme implementation in future studies. At postassessment, there were also differences in TAM scores among the three remaining sites and, not surprisingly, these were associated with outcome measures (Ogden \& Halliday-Boykins, 2004).

Another limitation was the high rate of missing school behaviour data, a problem noticed in other MST studies as well (Brown et al., 1999). While the general retention rate was high (92\%), only half of the participants were attending school on a regular basis, and even among these, non-attendance and irregular teacher contact made school ratings difficult. Although the results from our teacher reports analyses are in congruence with both our other results and our hypotheses, we recommend that future investigations pay particular attention to these adolescents' school careers and to the reasons why so few continue their formal schooling compared to their same aged peers.

While parents and teachers saw many positive behavioural changes in the adolescents, the self-reports were less consistent and encouraging. Investigating why MST seems to have less impact on the adolescents' own perception of their behaviour is beyond the scope of this study, though it encourages us, in the future, to look closer at how multisystemic treatment is experienced by the youths themselves.

\section{References}

Achenbach, T.M. (1991a). Manual for the Child Behaviour Checklist and 1991 profile. Burlington: University of Vermont, Department of Psychiatry.

Achenbach, T.M. (1991b). Manual for the Youth Self-Report and 1991 profile. Burlington: University of Vermont, Department of Psychiatry.

Achenbach, T.M. (1991c). Manual for the Teacher's Report Form and 1991 profile. Burlington: University of Vermont, Department of Psychiatry.

Aos, S., Lieb, R., Mayfield, J., Miller, M., \& Pennuci, A. (2004). Benefits and costs of prevention and early intervention programs for youth. Olympia, Washington: State Institute for Public Policy.

Borduin, C.M., Mann, B.J., Cone, L.T., Henggeler, S.W., Fucci, B.R., Blaske, D.M., \& Williams, R.A. (1995). Multisystemic treatment of serious juvenile offenders: Long-term prevention of criminality and violence. Journal of Consulting and Clinical Psychology, 63, 569-578.

Brown, T.L., Henggeler, S.W., Schoenwald, S.K., Brondino, M.J., \& Pickrel, S.G. (1999). Multisystemic treatment of substance abusing and dependent juvenile delinquents: Effects on school attendance at post-treatment and 6-month follow up. Children's Services: Social Policy, Research and Practice, 2, 81-93.

Capaldi, D.M., Stoolmiller, M., Clark, S., \& Owen, L.D. (2002). Heterosexual risk behaviors in at-risk young men from early adolescence to young adulthood: Prevalence, prediction, and association with STD contraction. Developmental Psychology, 8, 394-406.

Cunningham, P.B., Henggeler, S.W., Brondino, M.J., \& Pickrel, S.G. (1999). Testing underlying assumptions of the family empowerment perspective. Journal of Child and Family Studies, 8, 437-449.

Curtis, N.M., Ronan, K.R., \& Borduin, C.M. (2004). Multisystemic treatment: A meta-analysis of outcome studies. Journal of Family Psychology, 18, 411-419.
Elliott, D.S. (1998). Blueprints for violence prevention. Boulder, CO: University of Colorado, Center for the Study and Prevention of Violence. Blueprints Publications.

Elliott, D.S., Ageton, S.S., Huizinga, D., Knowles, B.A., \& Canter, R.J. (1983). The prevalence and incidence of delinquent behaviour: 1976-80. (Report of the National Youth Survey, Project Rept.\#26). Boulder, CO: Behavioural Research Institute.

Ferrer-Wreder, L., Stattin, H., Lorente, C.C., \& Adamson, L. (2004). Successful prevention and youth development programs across borders. New York: Kluwer Academic/Plenum Publishers.

Halliday-Boykins, C.A., \& Henggeler, S.W. (2001). Multisystemic treatment: Theory, research and practice. In E. Walton, P.A. Sandau-Beckler \& M. Mannes (Eds.), Balancing family-centered services and child-well being: Exploring issues in theory, practice, theory and research. New York: Columbia University Press.

Heinrichs, B. (2003). Self-reported delinquency (Fast Track Project Technical Report). Available from the Fast Track Project, http://www.fasttrackproject.org.

Henggeler, S.W., \& Borduin, C.M. (1992). Multisystemic therapy adherence scales. Unpublished instrument, Department of Psychiatry and Behavioural Sciences, Medical University of South Carolina.

Henggeler, S.W., Clingempeel, W.G., Brondino, M.J., \& Pickrel, S.G. (2002). Four-year follow-up of multisystemic therapy with substance abusing and dependent juvenile offenders. Journal of the American Academy of Child and Adolescent Psychiatry, 41, 868-874.

Henggeler, S.W., \& Lee, T. (2003). Multisystemic treatment of serious clinical problems. In A.E. Kazdin \& J.R. Weisz (Eds.), Evidence-based psychotherapies for children and adolescents. New York: Guilford Press.

Henggeler, S.W., Melton, G.B., Brondino, M.J., Scherer, D.G., \& Hanley, J.H. (1997). Multisystemic therapy with violent and chronic juvenile offenders and their families: The role of treatment fidelity in successful dissemination. Journal of Consulting and Clinical Psychology, 65, 821-833.

Henggeler, S.W., Melton, G.B., \& Smith, L.A. (1992). Family preservation using multisystemic therapy: An effective alternative to incarcerating serious juvenile offenders. Journal of Consulting and Clinical Psychology, 60, 953-961.

Henggeler, S.W., Pickrel, S.G., \& Brondino, M.J. (1999). Multisystemic treatment of substance abusing and dependent delinquents: Outcomes, treatment fidelity, and transportability. Mental Health Services Research, 1, 171-184.

Henggeler, S.W., \& Schoenwald, S.K. (1999). The role of quality assurance in achieving outcomes in MST programs. Journal of Juvenile Justice and Detention Services, 14, 1-17.

Henggeler, S.W., Schoenwald, S.K., Borduin, C.M., Rowland, M.D., \& Cunningham, P.B. (1998). Multisystemic treatment of antisocial behaviour in children and adolescents. New York: Guilford Press.

Huey, S.J., Jr., Henggeler, S.W., Brondino, M.J., \& Pickrel, S.G. (2000). Mechanisms of change in multisystemic therapy: Reducing delinquent behaviour through therapist adherence and improved family and peer functioning. Journal of Consulting and Clinical Psychology, 68, 451-467.

Larsson, B., \& Frisk, M. (1999). Social competence and emotional/behaviour problems in 6-16 year old Swedish school children. European Child and Adolescent Psychiatry, 8, 24-33.

Le Blanc, M. (1992). Family dynamics, adolescent delinquency, and adult criminality. Psychiatry: Interpersonal and Biological Processes, 55, 336-353.

Leschied, A., \& Cunningham, A. (2002). Seeking effective interventions for serious young offenders: Interim results of a four-year randomised study of multisystemic therapy in Ontario, Canada. London, Canada: Centre for Children and Families in the Justice System. 
Leve, L.D., Chamberlain, P., \& Reid, J.B. (2005). Intervention outcomes for girls referred from juvenile justice: Effects on delinquency. Journal of Consulting and Clinical Psychology.

Levine, S.Z., \& Jackson, C.J. (2004). Eysenck's theory of crime revisited: Factors or primary scales? Legal and Criminological Psychology, 9, 135-152.

Lipsey, M.W. (1999). Can rehabilitative programs reduce the recidivism of juvenile offenders? An inquiry into the effectiveness of practical programs. Virginia Journal of Social Policy and the Law, 6, 611-641.

Loeber, R., \& Farrington, D.P. (Eds.) (1998) Serious and violent juvenile offenders. Risk factors and successful interventions. Thousand Oaks, Ca: Sage.

Lösel, F. (1993). Evaluation of psychosocial interventions in prison and other penal contexts. I. Psychosocial interventions in the criminal justice system. Report presented to the 20th Criminological Research Conference. Council of Europe. European Committee on Crime Problems. Criminological Research, Vol. XXXI.

Nøvik, T.S. (1999). Validity and use of the Child Behaviour Checklist in Norwegian children and adolescents. An epidemiological and clinical study. Doctoral dissertation, University of Oslo, Centre for Child and Adolescent Psychiatry.

Nygren, P. (2000). I krysningsfeltet mellom barnevern og barneog ungdomspsykiatri. (Eng. In the crossing between child welfare and child- and adolescent psychiatry) Dobbeltklientprosjektet - delrapport 1. Oslo kommune, barne- og familieetaten, Rapportserie nr 1/2000.
Ogden, T., \& Halliday-Boykins, C.A. (2004). Multisystemic treatment of antisocial adolescents in Norway: Replication of clinical outcomes outside of the US. Child and Adolescent Mental Health, 9, 76-82.

Schaeffer, C.M., \& Borduin, C.M. (2005). Long term follow-up to a randomised clinical trial of multisystemic therapy with serious and violent juvenile offenders. Journal of Consulting and Clinical Psychology.

Schoenwald, S.K., Henggeler, S.W., Brondino, M.J., \& Rowland, M.D. (2000). Multisystemic therapy: Monitoring treatment fidelity. Family Process, 39, 83-103.

Schwartz, J.A.J., Gladstone, T.R.G., \& Kaslow, N.J. (1998). Depressive disorders. In T.H. Ollendick and M. Hersen (Eds.), Handbook of child psychopathology. New York: Plenum Press.

Storvoll, E. (1997). Barn og unge med alvorlige atferdsvansker: Hvem er de, og hvilken hjelp blir de tilbudt? (Eng. Children and youth with serious behaviour problems: Who are they, and what kind of help are they offered?) Report 21, Oslo: NOVA.

Tabachnick, B.G., \& Fidell, L.S. (2001). Using multivariate statistics (4th ed.). Needham Heights, MA: Allyn and Bacon.

Wasserman, G.A., \& Miller, L.S. (1998). The prevention of serious and violent juvenile offending. In R. Loeber \& D.P. Farrington (Eds.), Serious and violent juvenile offenders. Risk factors and successful interventions. Thousand Oaks, Ca: Sage. 
Copyright of Child \& Adolescent Mental Health is the property of Blackwell Publishing Limited and its content may not be copied or emailed to multiple sites or posted to a listserv without the copyright holder's express written permission. However, users may print, download, or email articles for individual use. 